International Journal of Clinical \& Experimental Otolaryngology (IJCEO)

ISSN 2572-732X

\title{
Extrahepatic Nasal Manifestations of Hepatitis C Virus
}

\author{
Amr El-Shazly \\ Department of Otolaryngology, Liège University Hospital (Centre Hospitalier Universitaire de Liège), Laboratory of Experimental Pathology-Experi- \\ mental Rhinology Unit Liège, Belgium.
}

\section{*Corresponding Author:}

Amr El-Shazly,

Department of Otolaryngology, Liège University Hospital (Centre Hospitalier Universitaire de Liège), Laboratory of Experimental PathologyExperimental Rhinology Unit Liège, Belgium.

Tel: +3243667269

Fax: +3243667525

E-mail: amrel_shazly@hotmail.com

Received: August 21, 2015

Published: August 24, 2015

Citation: Amr El-Shazly (2015) Extrahepatic Nasal Manifestations of Hepatitis C Virus. Int J Clin Exp Otolaryngol. 01(1e), 1-2. doi: http://dx.doi.org/10.19070/2572-732X-150001e

Copyright: Amr El-Shazly ${ }^{\mathcal{C}}$ 2015. This is an open-access article distributed under the terms of the Creative Commons Attribution License, which permits unrestricted use, distribution and reproduction in any medium, provided the original author and source are credited.

The nose is a competent immunological organ that reflects many of the cellular and molecular events seen in mucosal immunity. Viruses are major causative agents for respiratory tract infections in children and adults. Viruses induced rhinitis is usually of acute nature resulting in the common cold symptoms; rhinorrhea, nasal obstruction, malaise and exacerbation of already existing airways disease. Among the viruses frequently infecting the human nose are the RNA virus such as coronavirus, rhinovirus, and the influenza/parainfluenza virus and the double-stranded DNA adenovirus. These viruses induce rhinitis (common cold and flu) by attaching themselves to the lining of the nose and paranasal sinuses.

Other chronic blood borne viruses may produce rhinopathy. Examples of such viruses are the human acquired immune deficiency virus (HIV) and hepatitis $\mathrm{C}$ virus (HCV). While the rhinosinusitis seen in HIV population is due to superinfection with other pathogens due to the general weak immunological system caused by HIV, the rhinosinusitis seen in HCV could be due to specific nasal immunological response.

HCV which belongs to lenti viruses is known to be associated with head and neck diseases. Thyroid disease is commonly seen in people with HCV. Correlation between HCV and lymphocytic sialoadenitis, similar to sialoadenitis associated with idiopathic Sjögren syndrome has been also described [1], but nasal extrahepatic manifestations of $\mathrm{HCV}$ is poorly defined except for $\mathrm{HCV}$ being a recognized cause of epistaxis. This is attributed to its effect on the coagulation profile secondary to hepatic failure. However, clinical experience tells that many of $\mathrm{HCV}$ positive patients with normal coagulation profile and liver functions present to ENT OPD with recurrent mild to moderate epistaxis. This was investigated by the author and coworkers, by conducting questionnaire asking about the incidence and severity of recurrent epistaxis in healthy controls vs HCV patients with no liver cirrhosis and normal coagulation profile. As seen in figure 1 there was a real increase incidence for epistaxis in $\mathrm{HCV}$ positive patients over the control group (Figure 1A). The epistaxis ranged between mild, moderate and severe (Figure 1B).

This opened a channel for an important question why do these patients develop recurrent epistaxis despite normal coagulation profile. This was at least partially answered in a study that reported that $\mathrm{HCV}$ infection induces mild to moderate nasal fibrosis and epithelial erosion but with subclinical rhinitis [2]. In this article the authors investigated nasal biopsies from 20 patients, presenting with recurrent epistaxis with HCV infection but with no liver cirrhosis and with normal liver function tests, and from 10 control subjects. All biopsies were subjected to real time polymerase chain reaction (RT-PCR) as well as histology. Their results showed that $60 \%$ of $\mathrm{HCV}$ positive samples showed nasal epithelial erosion, $95 \%$ showed subepithelial non-specific inflammation and/or fibrosis, while only $5 \%$ showed normal histology. However, none of the twenty PCR samples showed the presence of HCV nucleic acids sequences in the nasal tissues. On the other hand, all control subjects had normal histology and the absence of the viral $\mathrm{m}$ RNA in the PCR $(100 \%)$.

Another important question that seems to have controversial answer based on current available literature; is the nose a potential route of transmission for HCV. Despite hepatocytes being the major site of infection, there is a growing body of evidence to suggest that HCV can replicate efficiently in extrahepatic tissues and cell types [3]. Furthermore, the potential role of body fluids in virus transmission has been investigated and showed HCV RNA detection in $76.5 \%(39 / 51)$ of the sera and in $9.8 \%(5 / 51)$ of the tear fluid samples from 51 patients of chronic hepatitis $\mathrm{C}$ [4]. Other studies had also demonstrated a positive reaction in HCV-RNA PCR from plasma, tear fluid and eye swabs but not from nasal and pharyngeal swabs [5, 6]. Perhaps the stage and the activity of the hepatic disease may influence the intranasal transmission of HCV. Aaron et al [7] studied intranasal drug users with chronic active HCV infection and found the presence of blood (74\%) and HCV RNA (13\%) in the nasal secretions. Interestingly, the authors also reported the presence of blood $(8 \%)$ and HCV RNA $(5 \%)$ in the drug sniffing implements of $\mathrm{HCV}$-infected intranasal drug users.

El-shazly et al [8] studied the histopathological mucosal remod- 
Figure 1. (A). Percentage of control subjects vs HCV positive patients with normal coagulation profile and no active hepatic disease, reporting epistaxis. Total number of participants is $100 ; 50$ control and 50 with HCV infection. Asterisk indicates statistical significance by fisher's exact test. (B) Severity of epistaxis. Y axis represents the number of patients presenting with different severity of epistaxis $n=10$ for mild, $n=9$ for moderate and $n=7$ for severe.

(A). Percentage of subjects presenting with epistaxis.

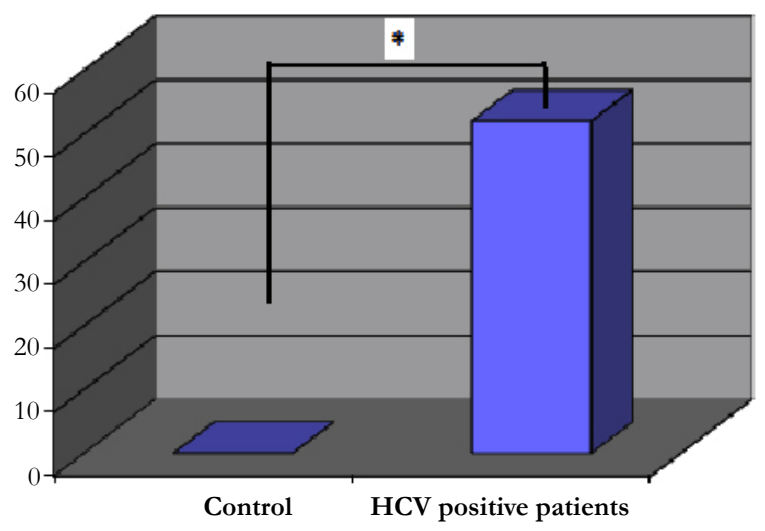

(B). Severity of epistaxis.

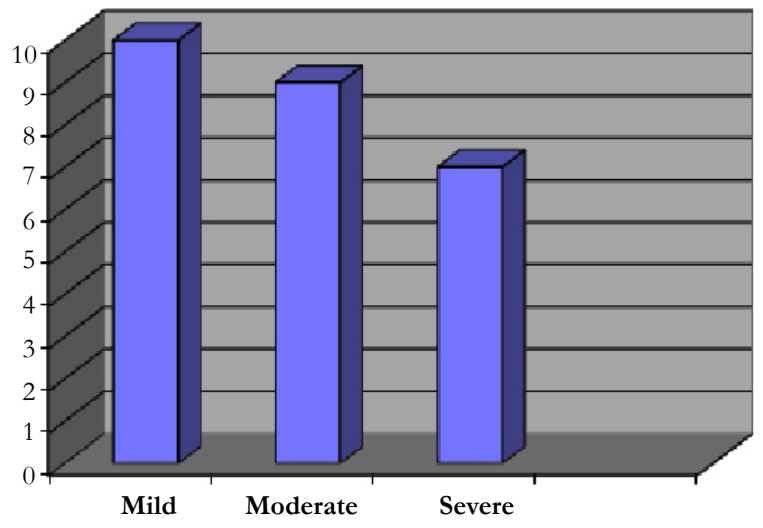

eling in patients with different genotype HCV infection without liver cirrhosis. The authors found that patients with different HCV genotype infections, who presented with either severe chronic rhinosinusitis (CRS) or subclinical rhinitis, demonstrated a similar pattern of nasal epithelial erosion that was independent of ethnicity, but correlated with the severity of rhinitis. Patients with $\mathrm{HCV}$ infection and severe CRS demonstrated a significant lymphocytic and neutrophil infiltration of their nasal mucosa. This was in consistence with nasal cytology which showed also neutrophils infiltration. $\operatorname{IgA}$ and $\operatorname{IgD}$ were also detected selectively in the extracellular nasal tissues in HCV-infected subjects whether with CRS or subclinical rhinitis. These histopathological changes in the nasal tissue of patients with HCV indicate that a specific cellular and humoral immunological response takes place in the nasal mucosa against HCV.

It could be concluded from all of the above that although there is increasing evidence pointing to HCV induced rhinopathy, our current knowledge is still insufficient. While the nasal epithelial erosion seen in HCV infected patients with or without clinical rhinosinusitis explains at least in part the recurrent epistaxis seen in these patients even when there is no active hepatic disease and normal coagulation profile, the other cellular and humoral responses resulting into nasal mucosa remodeling needs to be further studied to translocate them to possible clinical presentation.

Rhinologists need to further study HCV induced rhinopathy. Whether the nasal remodeling seen in HCV infection increases the nasal non-specific hyper responsiveness remain to be ex- plored. Well controlled studies of CT-scans of paranasal sinuses in patients with $\mathrm{HCV}$ at different stage of their hepatic disease activity vs control subjects may further define whether these patients also carry higher incidence in developing clinical rhinosinusitis. Large multi- center studies providing nasal biopsies from patients with different genotype of $\mathrm{HCV}$ infection may further define the nasal remodeling and whether the nasal tissue harbors the virus genome.

\section{References}

[1]. Galossi A, Guarisco R, Bellis L, Puoti C (2007) Extrahepatic manifestations of chronic HCV infection. J Gastrointestin Liver Dis 16(1): 65-73.

[2]. Abbas F, Refaat L, Hussein A, El-Shazly AE (2009) Hepatitis C virus induces nasal epithelial erosion and sub-epithelial rhinitis. Rhinology 47(4): 438-443.

[3]. Blackard JT, Kemmer N, Sherman KE (2006) Extrahepatic replication of HCV: insights into clinical manifestations and biological consequences. Hepatology 44(1): 15-22.

[4]. Mendel I, Muraine M, Riachi G, el Forzli F, Bertin C, et al. (1997) Detection and genotyping of the hepatitis $C$ RNA in tear fluid from patients with chronic hepatitis C. J Med Virol 51(3): 231-233.

[5]. Sterling RK, Bralow $S$ (2006) Extrahepatic manifestations of hepatitis $C$ virus. Curr Gastroenterol Rep 8(1): 53-59.

[6]. Lormeau C, Falgarone G, Roulot D, Boissier MC (2006) Rheumatologic manifestations of chronic hepatitis $\mathrm{C}$ infection. Joint Bone Spine 73(6): 633638.

[7]. Aaron S, McMahon JM, Milano D, Torres L, Clatts M, et al. (2008) Intranasal transmission of hepatitis $C$ virus: virological and clinical evidence. Clin Infec Dis 47(7): 931-934.

[8]. El-Shazly A, Arafa M, Roncarati P, Dortu E, Lefebvre PP, et al. (2010) Characterization of Hepatitic $\mathrm{C}$ virus induced nasal mucosa remodelling. Histopathology 57(3): 488-492. 